\title{
Effect of applied compressive stress and impregnation material on internal strain and stress state in $\mathrm{Nb}_{3} \mathrm{Sn}$ Rutherford cable stacks
}

\author{
F. Wolf, C. Scheuerlein, M. Lorentzon, B. Katzer, M. Hofmann, W. Gan, F. Lackner, D. Schoerling, D. Tommasini, \\ F. Savary, L. Bottura
}

\begin{abstract}
The $\mathrm{Nb}_{3} \mathrm{Sn}$ superconductor in accelerator magnets must resist high mechanical stresses. In order to understand better the effect of the coil impregnation system on the stresses exerted on the strain-sensitive $\mathrm{Nb}_{3} \mathrm{Sn}$ superconductor, we have measured the elastic strain evolution in the conductor constituents under externally applied loads. For this purpose a dedicated load frame that enables rotation of the sample load axis with respect to the neutron scattering geometry was installed in the Stress-Spec beamline at the neutron source Heinz Maier-Leibnitz FRM II. The $\mathrm{Nb}_{3} \mathrm{Sn}$ and $\mathrm{Cu}$ loading strain was measured in situ by neutron diffraction under monotonic and cyclic compressive loading. Socalled ten-stack samples composed of $\mathrm{Nb}_{3} \mathrm{Sn}$ Rutherford type cable with different impregnation, and coil blocks extracted from a $11 \mathrm{~T}$ dipole short model coil were investigated.
\end{abstract}

Index Terms - $\mathrm{Nb}_{3} \mathrm{Sn}$, Rutherford cable, superconducting magnet coil, mechanical properties, neutron diffraction

\section{INTRODUCTION}

$I^{\mathrm{N}}$ $\mathrm{N}$ accelerator magnets [1] like the $\mathrm{Nb}_{3} \mathrm{Sn}$ magnets presently under construction for the LHC High Luminosity upgrade (HL-LHC) [2], and those foreseen for the Future Circular Collider (FCC) [3], the dominant mechanical load case to which the coils are exposed is transverse compression.

Transverse compressive stress can degrade the superconducting properties of the strain sensitive $\mathrm{Nb}_{3} \mathrm{Sn}$ [4]. A permanent conductor damage occurs when at room temperature the mechanical stresses exceed about $150 \mathrm{MPa}$, [5]. Therefore, this stress level must not be exceeded during coil manipulations and magnet assembly. Cold tests of the TQS03 magnet indicate that at $1.9 \mathrm{~K}$ the $\mathrm{Nb}_{3} \mathrm{Sn}$ conductor in the magnet coils can withstand higher stresses up to $200 \mathrm{MPa}$ without strong permanent degradation [6].

The impregnation of the conductor block with an epoxy resin is assumed to be crucial to improve the stress resistance of the $\mathrm{Nb}_{3} \mathrm{Sn}$ conductor. In order to understand better the $\mathrm{Nb}_{3} \mathrm{Sn}$ degradation mechanisms and the effect of the epoxy impregnation on the conductor stress tolerance, we have measured by neutron diffraction the $\mathrm{Nb}_{3} \mathrm{Sn}$ and $\mathrm{Cu}$ elastic strain evolution as a function of externally applied loads.

F. Wolf. C. Scheuerlein, M. Lorentzon, B. Katzer, F. Lackner, D. Schoerling, D. Tommasini, F. Savary and L. Bottura are with CERN, 1211 Geneva, Switzerland. Corresponding author: Christian.Scheuerlein@ cern.ch.

\section{EXPERIMENTAL}

\section{A. The samples}

For the neutron diffraction experiments cubes with approximate dimensions of $15 \times 15 \times 15 \mathrm{~mm}^{3}$ were machined out of the $\mathrm{Nb}_{3} \mathrm{Sn} 11 \mathrm{~T}$ dipole [7], [8] coil \#107 that previously had been cold tested in a short model magnet. $15 \mathrm{~mm}$ thick coil slices were cut from the coil using a diamond saw, and afterwards one conductor block composed of 8 Rutherford cables was machined out of the slices. Previous neutron diffraction examination of coil \#107 has shown that after magnet cold testing and disassembly the residual stresses in this conductor block are small [9].

A coil block sample and a metallographic coil cross section are presented in Fig. 1. The average cable thickness in the $11 \mathrm{~T}$ dipole coil of $1.054 \pm 0.208 \mathrm{~mm}$ has been determined by digital image analysis of $11 \mathrm{~T}$ coil \#107 micro-tomography slices [10].

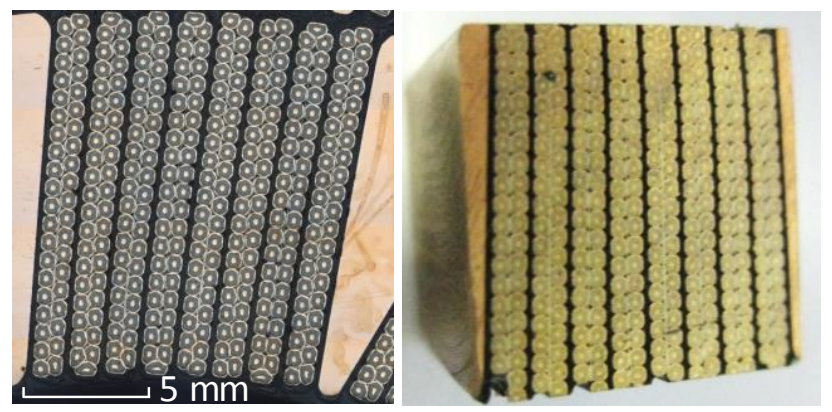

Fig. 1. Metallographic cross section of conductor block in $11 \mathrm{~T}$ dipole coil, and extracted conductor block segment for combined neutron diffraction and compression tests.

A second sample type are so-called ten-stack samples. These samples are made of ten $\mathrm{Nb}_{3} \mathrm{Sn} 11 \mathrm{~T}$ dipole cables that are stacked alternatingly in order to compensate for the cable keystone angle [11]. The cables have been stacked in a reaction fixture and followed the same reaction heat treatment cycle as the $11 \mathrm{~T}$ dipole coils. Fig. 2 shows an epoxy impregnated $\mathrm{Nb}_{3} \mathrm{Sn} 11 \mathrm{~T}$ dipole cable stack with the definition of the three measurement directions.
M. Hofmann is with Forschungsneutronenquelle Heinz Maier-Leibnitz (FRM II), TU München, Germany. W. Gan is with German Engineering Materials Science Centre at MLZ, Helmholtz-Zentrum Geesthacht, Germany. 


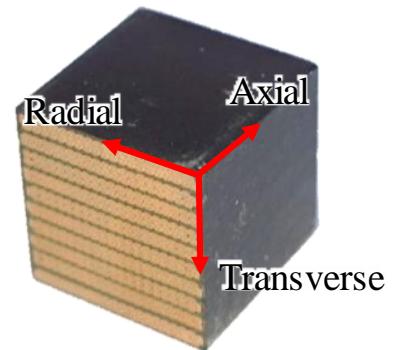

Fig. 2. Cable stack with definition of the sample orientations axial, radial and transverse with respect to the cable arrangement.

All samples are made of Rutherford type cables consisting of the Restacked Rod Process (RRP) type wires [12]. The $11 \mathrm{~T}$ dipole cable with a nominal width of $14.7 \mathrm{~mm}$ consists of 40 RRP 144/169 wires with a nominal diameter of $0.7 \mathrm{~mm}$ and $\mathrm{Cu}$ to non- $\mathrm{Cu}$ ratio of about 1.15 . It has a $25 \mu \mathrm{m}$-thick stainless steel core, and a $0.155 \mathrm{~mm}$-thick surrounding cable insulation made of a mica tape $(0.08 \mathrm{~mm})$ and fibre braiding $(0.075 \mathrm{~mm})$. Subsequent to the reaction heat treatment the void space in the brittle coils is filled with epoxy resin CTD-101K from Composite Technology Development [13], in order to improve the electromechanical coil properties.

The impact of the impregnation material on the $\mathrm{Nb}_{3} \mathrm{Sn}$ loading strain evolution was studied by comparing the effect of external stress on epoxy impregnated samples and nonimpregnated samples. In addition, ten-stack samples where the wires of the adjacent cables were soldered together and the inter cable void space was partly filled with $\mathrm{Sn} 96 \mathrm{Ag} 4$ solder were studied.

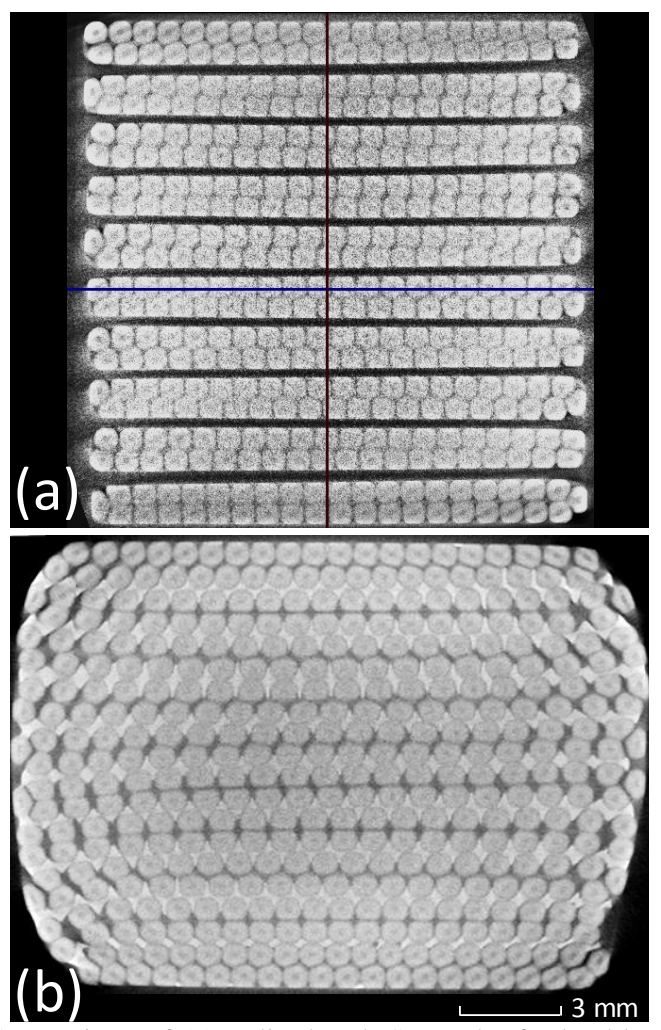

Fig. 3. Comparison of $11 \mathrm{~T}$ dipole $\mathrm{Nb}_{3} \mathrm{Sn}$ Rutherford cable ten-stack sample tomograms (a) epoxy impregnated and (b) partly filled with Sn96Ag4 solder. The epoxy impregnated and Sn96Ag4 filled samples were compressed in transverse direction up to $200 \mathrm{MPa}$ and $150 \mathrm{MPa}$, respectively.
In order to produce $\mathrm{Sn} 96 \mathrm{Ag} 4$ solder filled ten-stack samples, an alternating cable ten-stack of solder stripes and cables was prepared. To fill the voids with solder it was necessary to remove the insulation from the reacted cable. To get a proper contact between each cable and the solder, a thin layer of solder flux Gel Mob 39 was applied to the cable and the solder stripes. The heat-treatment to melt the solder was performed in a dedicated aluminum mold equipped with two regulated heating cartridges and a thermocouple.

The soldering temperature may have an effect on the composite sample strain state because of the thermal expansion mismatch between the Sn96Ag4 solder and the other sample constituents. The heat treatment cycle consisted of two temperature plateaus, $150{ }^{\circ} \mathrm{C}-2$ minutes to exceed the flash point of the flux, and $230^{\circ} \mathrm{C}-0.5$ minutes to melt the solder.

After compression tests, cross sections of the epoxy impregnated and Sn96Ag4 filled ten-stack samples have been obtained by non-destructive X-ray micro-tomography (Fig. 3). A very strong buckling of the Sn96Ag4 filled sample is observed after application of a transverse compressive stress of $150 \mathrm{MPa}$, while no strong buckling effect is seen on epoxy impregnated sample after application of $200 \mathrm{MPa}$ transverse stress.

\section{B. Compressive stress-strain measurements}

Compressive stresses were applied in transverse load direction using a load frame with a load capacity of up to $50 \mathrm{kN}$. A maximum transverse compressive stress of $220 \mathrm{MPa}$ can be applied on the samples with $225 \mathrm{~mm}^{2}$ cross section. In order to reduce friction effects PTFE spray was applied onto the sample surfaces in contact with the pressing tool. Force measurements were performed with a HBM Typ $0350 \mathrm{kN}$ load cell, and the sample strain was measured with an Instron 2620-602 extensometer. All experiments were started with a compressive preload of about $0.2 \mathrm{kN}$, with applied stress steps of $15 \mathrm{MPa}$, and the load rate between the stress plateaus was always $50 \mathrm{~N} / \mathrm{s}$. For more information about the stress-strain measurements see reference [14].

\section{Neutron diffraction measurements}

Relative changes of lattice plane distances in transverse, axial and radial sample directions (Fig. 2) have been measured by neutron diffraction at the Stress-Spec beamline of MLZ [15]. The loading strain is determined from the scattering angles of the $\mathrm{Nb}_{3} \mathrm{Sn}$ (321) and $\mathrm{Cu}$ (220) lattice planes [16] and represents an average elastic strain in the gauge volume of $5 \times 5 \times 5 \mathrm{~mm}^{3}$ defined by beam and detector characteristics.

Table I summarizes Young's moduli $E_{h k l}$ and Poisson's ratio $v_{h k l}$ that are calculated from single crystal constants by the Kroener model [17], which was used as it is the most accepted approach [16] to calculate the elastic constants. As the principal stress directions are known, the stress tensor can be determined at one point with strain measurements in just three directions.

More details about the neutron diffraction measurement and calculation of loading strains and loading stresses can be found in reference [18]. 
TABLE I

SINGLE CRYSTAL ELASTIC CONSTANTS OF NB $\mathrm{S}_{3} \mathrm{SN}$ [19] AND CU [20] WITH CORRESPONDING ELASTIC CONSTANTS CALCULATED BY THE KROENER

\begin{tabular}{lllllll}
\hline \hline & $h k l$ & $\mathrm{C}_{11}$ & $\mathrm{C}_{12}$ & $\mathrm{C}_{44}$ & $E_{h k l}$ & $v_{h k l}$ \\
& & $\mathrm{GPa}$ & $\mathrm{GPa}$ & $\mathrm{GPa}$ & $\mathrm{GPa}$ & \\
\hline $\mathrm{Nb}_{3} \mathrm{Sn}$ & 321 & 253.8 & 112.4 & 39.57 & 131.2 & 0.363 \\
$\mathrm{Cu}$ & 220 & 1684 & 1214 & 754 & 138.9 & 0.333 \\
\hline \hline
\end{tabular}

\section{RESULTS}

\section{A. Effect of impregnation on $\mathrm{Nb}_{3}$ Sn loading strains}

Fig. 4 compares the $\mathrm{Nb}_{3} \mathrm{Sn}$ (321) loading strains in the three principal directions for four different Rutherford cable stacks. The impact of the impregnation material on the $\mathrm{Nb}_{3} \mathrm{Sn}$ (321) strain evolution is clearly revealed.

The Sn96Ag4 filling of the cable stack causes a strong buckling under transverse compression, as can be seen in the tomographic cross sections shown in Fig. 3. The $\mathrm{Nb}_{3} \mathrm{Sn}$ strains in the Sn96Ag4 filled ten-stack are even higher than in the nonimpregnated cable stack (Fig. 4). Lowest $\mathrm{Nb}_{3} \mathrm{Sn}$ loading strains have been measured in the epoxy impregnated samples.
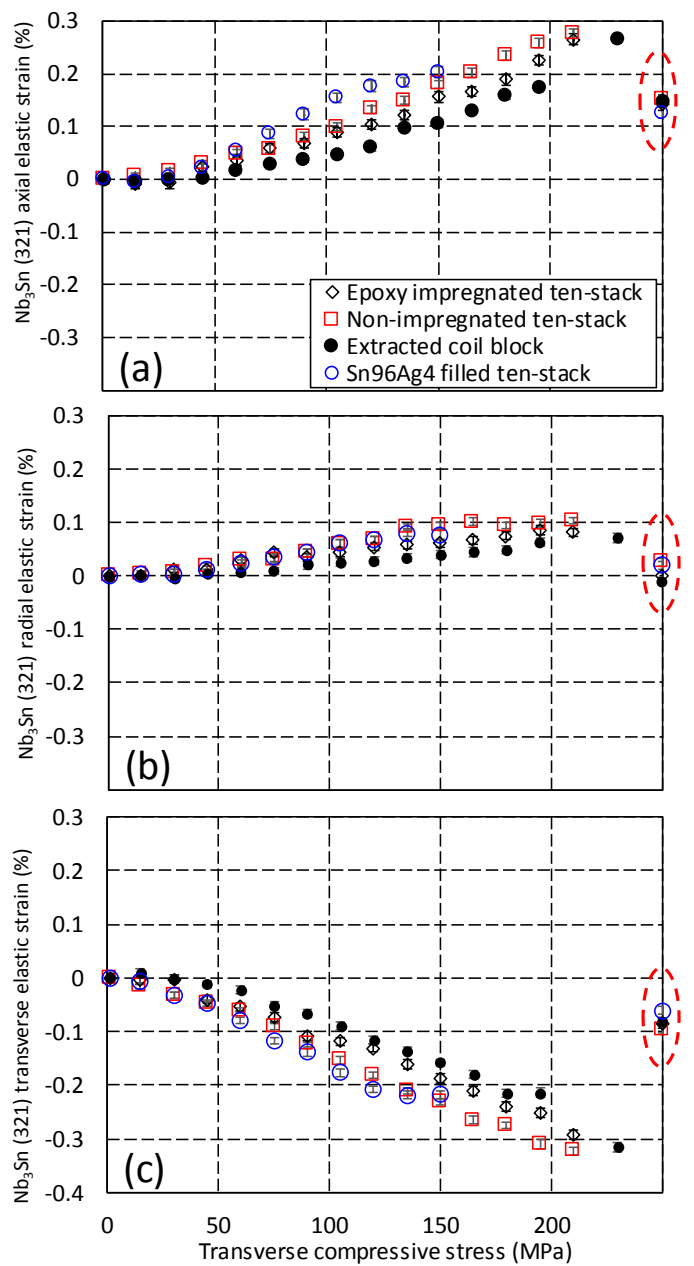

Fig. 4. Comparison of the $\mathrm{Nb}_{3} \mathrm{Sn}$ (321) loading strain evolution during application of transverse compressive stress in (a) axial, (b) radial and (c) transverse directions. The data points encircled with red dashed lines have been measured after releasing the external stress.

\section{B. Effect of impregnation material on $\mathrm{Nb}_{3} \mathrm{Sn}$ stress homogeneity}

$\mathrm{The} \mathrm{Nb}_{3} \mathrm{Sn}$ diffraction peak width changes upon application of mechanical load can be an indication of changes of the $\mathrm{Nb}_{3} \mathrm{Sn}$ loading stress homogeneity [18]. In Fig. 5 the evolution of the $\mathrm{Nb}_{3} \mathrm{Sn}$ (321) diffraction peak width at half maximum above the background (FWHM) during application of transverse compressive stress is compared for the studied sample types.

In the Sn96Ag4 solder filled cable stack the $\mathrm{Nb}_{3} \mathrm{Sn}$ (321) peak width increases when the externally applied load exceeds $50 \mathrm{MPa}$. In contrast, in the epoxy impregnated cable stacks the peak width changes only when the load exceeds $100 \mathrm{MPa}$.
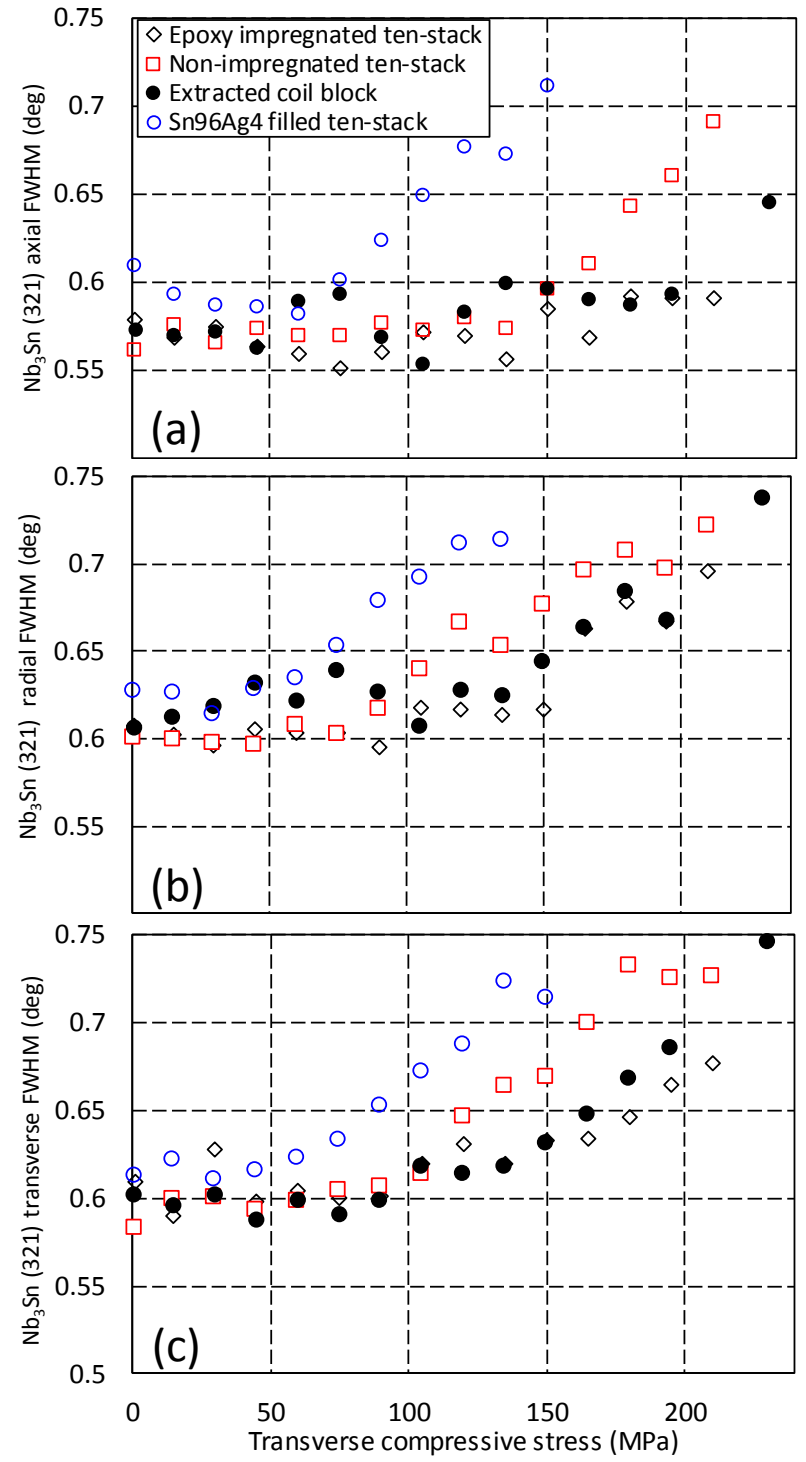

Fig. 5. Comparison of the $\mathrm{Nb}_{3} \mathrm{Sn}$ (321) diffraction peak width evolution during application of transverse compressive stress in (a) axial, (b) radial and (c) transverse directions.

\section{Cyclic transverse compressive loading of non- impregnated cable stack}

The loading strain and loading stress evolutions of $\mathrm{Nb}_{3} \mathrm{Sn}$ (321) and $\mathrm{Cu}$ (220) in a non-impregnated $11 \mathrm{~T}$ dipole Rutherford cable stack upon cyclic transverse compressive 
loading are shown in Fig. 6. The load has been increased in $15 \mathrm{MPa}$ steps. After each step the load was released to $1 \mathrm{MPa}$.

Under transverse compressive loading the $\mathrm{Nb}_{3} \mathrm{Sn}$ (321) and $\mathrm{Cu}$ (220) loading stresses in transverse direction are similar to the externally applied stress. This indicates iso-stress conditions in the conductor constituents when the load is applied perpendicularly to the $\mathrm{Nb}_{3} \mathrm{Sn}$ filament orientation [18].

The $\mathrm{Cu}$ transmits an iso-static pressure which corresponds to the externally applied stress. $\mathrm{The} \mathrm{Nb}_{3} \mathrm{Sn}$ filaments exert a stress of similar magnitude in the opposite direction. When releasing the externally applied load, the $\mathrm{Nb}_{3} \mathrm{Sn}$ and $\mathrm{Cu}$ loading stresses are released in the transverse direction, but not in the axial and radial directions.

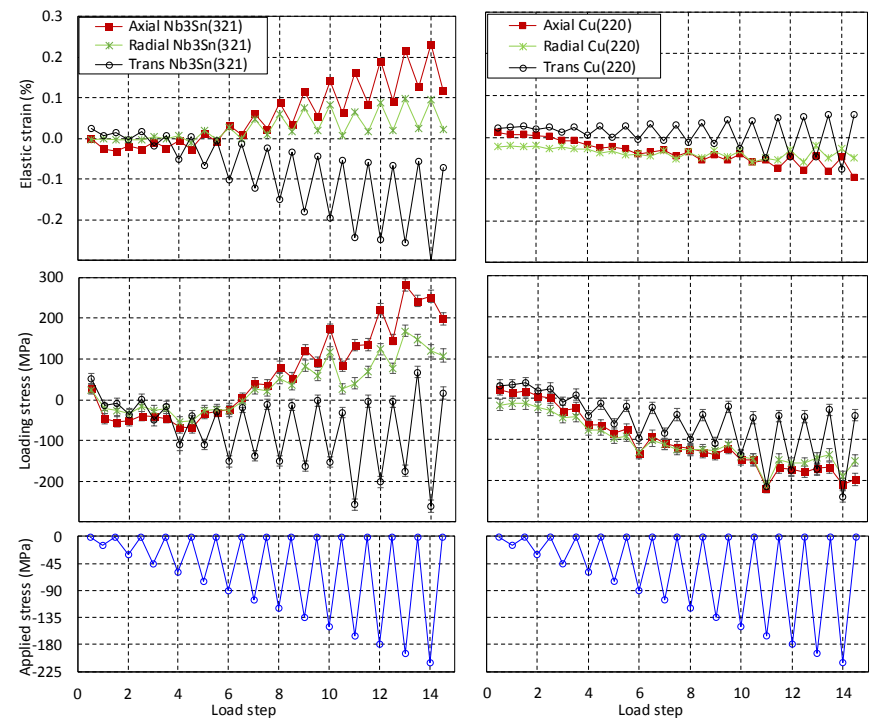

Fig. 6. $\mathrm{Nb}_{3} \mathrm{Sn}(321)$ and $\mathrm{Cu}(220)$ loading strain and stress evolution in axial, radial and transverse directions of non-impregnated ten-stack sample, as a function of cyclically applied transverse compressive stress. The load cycle is shown in the lower plot.

\section{Comparison of loading strains of non-impregnated ten-} stack and impregnated coil segment

The $\mathrm{Nb}_{3} \mathrm{Sn}$ (321) transverse and axial loading strain evolution in the non-impregnated ten-stack and extracted coil conductor block are compared in Fig. 7.

Elastic strain is calculated from the diffraction angle changes relative to those measured at zero load. For both sample types two experiments were performed, with monotonic or cyclic transverse stress application. For cyclic loading only the strain values measured at the stress maxima are shown. The same loading strains are observed, irrespectively of the monotonic or cyclic loading.

The comparison of the $\mathrm{Nb}_{3} \mathrm{Sn}$ loading strain evolution of both impregnated and both non-impregnated samples indicates an excellent reproducibility of the experiments. The epoxy impregnated samples exhibit comparatively lower loading strains than the non-impregnated samples.

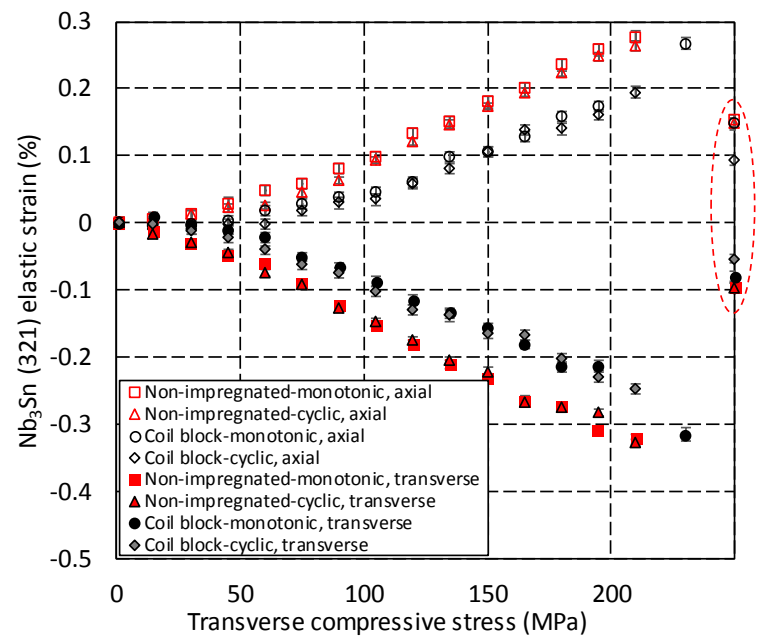

Fig. 7. Comparison of transvers and axial $\mathrm{Nb}_{3} \mathrm{Sn}$ (321) loading strain evolution under monotonic and cyclic loading as a function of compressive stress applied in transverse direction. Two identical nonimpregnated ten-stack samples, and two identical coil block samples from \#107 have been used. The data points encircled with red dashed lines have been measured after releasing the external stress.

\section{DISCUSSION AND CONCLUSION}

The HL-LHC $\mathrm{Nb}_{3}$ Sn coils made of Rutherford type cable can be considered as a fiber reinforced composite, where the $\mathrm{Nb}_{3} \mathrm{Sn}$ filaments represent the reinforcing fibers and the $\mathrm{Cu}$ and epoxy resin the matrix material. The combined neutron diffraction and stress-strain measurements have shown that when the load is applied in axial direction (the $\mathrm{Nb}_{3} \mathrm{Sn}$ wire drawing direction), the strain is equal in all coil constituents [18]. Assuming isostrain conditions of all composite materials, the coil stiffness in axial direction can be predicted by the rule of mixtures [21], taking into account the epoxy volume fraction in the coil [14].

When the compressive load is applied perpendicular to the reinforcing filaments drawing direction, composite theory predicts that the stress in all composite constituents is the same [22]. This is also confirmed by the loading stress results presented here for the $\mathrm{Nb}_{3} \mathrm{Sn}$ cable stacks. In the load direction the $\mathrm{Cu}$ and $\mathrm{Nb}_{3} \mathrm{Sn}$ stresses are identical, and $\mathrm{Cu}$ exhibits an isotropic pressure around the filaments. The $\mathrm{Cu}$ stress is similar to the externally applied stress.

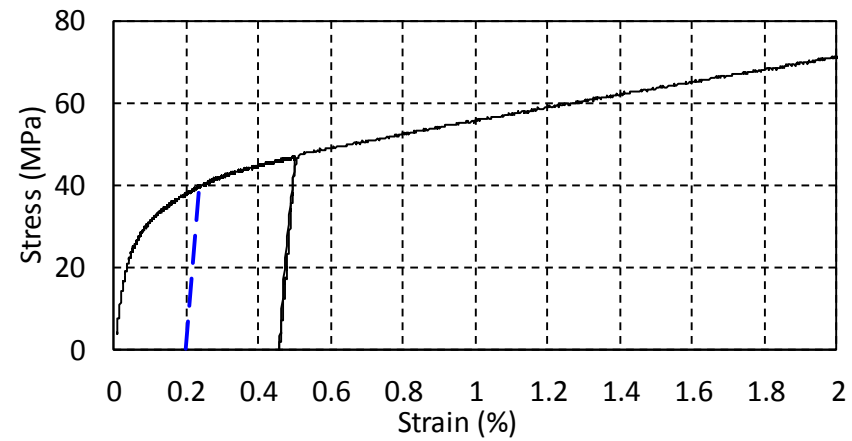

Fig. 8. Tensile stress-strain curve of an annealed copper wire with $R_{\mathrm{p} 0.2}$ indicated by the blue dashed line [23]. 
Materials cannot plastically yield under a hydrostatic load [24]. Therefore, under transverse compression the annealed $\mathrm{Cu}$ can carry high loads despite its very low yield stress (Fig. 8).

When the external stress is released the $\mathrm{Nb}_{3} \mathrm{Sn}$ and $\mathrm{Cu}$ stresses in the transverse load direction relax almost completely (Fig. 6). In axial and in radial directions the compressive force imposed by the $\mathrm{Cu}$ matrix is compensated by a corresponding tensile force in the $\mathrm{Nb}_{3} \mathrm{Sn}$ filaments. This load behavior may be different in real magnet coils, which are constraint in axial and radial directions.

The epoxy impregnation reduces the $\mathrm{Nb}_{3} \mathrm{Sn}$ loading strain (Fig. 4) and strain inhomogeneity (Fig. 5). Assuming iso-stress conditions, the epoxy E-modulus should not strongly effect the $\mathrm{Nb}_{3}$ Sn loading strain.

The solder filling has been attempted in order to study the effect of the impregnation material stiffness. The Sn96Ag4 E-modulus is about $50 \mathrm{GPa}$ [25] compared to the CDT-101K E-modulus of $3.8 \mathrm{GPa}$ [26]. The Sn96Ag4 filled ten-stack exhibits a comparatively higher $\mathrm{Nb}_{3} \mathrm{Sn}$ loading stress and $\mathrm{Nb}_{3} \mathrm{Sn}$ stress inhomogeneity. The reasons for the increased $\mathrm{Nb}_{3} \mathrm{Sn}$ loading stress and buckling of the $\mathrm{Sn} 96 \mathrm{Ag} 4$ filled tenstack sample may be related to the very low Sn96Ag4 yield stress, or to the solder connection of the adjacent cables. Such hypothesizes remain to be confirmed by further studies.

\section{ACKNOWLEDGMENTS}

We are grateful to the CERN central workshop team for the preparation of the $11 \mathrm{~T}$ dipole coil sample. This work is based upon experiments performed at the Stress-Spec instrument operated by FRM II at the Heinz Maier-Leibnitz Zentrum (MLZ), Garching, Germany. This work was supported in part by the European Commission under the FP7 project HiLumi LHC under Grant GA 284404, co-funded by the DoE, USA and KEK, Japan. This work was supported in part by the European Union's Horizon 2020 research and innovation programme under grant No 654305, EuroCirCol project and by the High Performance Center Simulation and Software Based Innovation.

\section{REFERENCES}

[1] L. Bottura, G. de Rijk, L. Rossi, E. Todesco, "Advanced accelerator magnets for upgrading the LHC," IEEE Trans. Appl. Supercond., vol. 22, no. 3, 2012, Art. no. 4002008

[2] The High Luminosity Large Hadron Collider, ed. O. Bruening and L. Rossi, World Scientific Publishing Co, 2015

[3] D. Tommasini et al., "The 16 T Dipole Development Program for FCC," IEEE Trans. Appl. Supercond., vol. 27, no. 4, June 2017.

[4] J.W. Ekin, "Effect of transverse compressive stress on the critical current and upper critical field of $\mathrm{Nb}_{3} \mathrm{Sn}^{\prime}$, J. Appl. Phys., vol. 62, 1987, pp. $4829-4834$

[5] P. Ebermann et al., "Characterization of irreversible degradation of $\mathrm{Nb}_{3} \mathrm{Sn}$ Rutherford cables due to transversal compression stress at room temperature", Supercond. Sci. Technol., vol. 31, 2018, Art. no. 065009

[6] G. Sabbi, " $\mathrm{Nb}_{3} \mathrm{Sn}$ IR Quadrupoles for the High Luminosity LHC", IEEE Trans. Appl. Supercond., vol. 23, no. 3, 2013, Art. no. 4000707

[7] M. Karppinen et al., "Design of $11 \mathrm{~T}$ twin-aperture dipole demonstrator magnet for LHC upgrades", IEEE Trans. App. Supercond., vol. 22, no. 3, June 2012, Art. no. 4901504
[8] F. Savary et al., "Progress on the Development of the $\mathrm{Nb}_{3} \mathrm{Sn} 11 \mathrm{~T}$ Dipole for the High Luminosity Upgrade of LHC," IEEE Trans. Appl. Supercond., vol. 27, no. 4, June 2017, Art. no. 4003505

[9] C. Scheuerlein, M. Di Michiel, M. Hofmann, M. Lorentzon, F. Lackner, R. Flükiger, F. Savary, L. Bottura, "Residual strain in the Nb3Sn 11 T dipole magnet coils for HL-LHC", Supercond. Sci. Technol., vol. 30, 2017, Aet. No. 125002

[10] U. Kelly, S. Richter, C. Redenbach, K. Schladitz, C. Scheuerlein, F. Wolf, P. Ebermann, F. Lackner, D. Schoerling, D. Meinel, “3D shape and cross sectional inhomogeneity of $\mathrm{Nb}_{3} \mathrm{Sn}$ superconducting wires in Rutherford cables“, IEEE Trans. Appl. Supercond., vol. 28, no. 4, 2018, Art. no. 4800705

[11] D.R. Chichili, T.T. Arkan, I. Terechkine, J.A. Rice, "Niobium-Tin Magnet Technology Development at Fermilab", Proceedings of the 1999 Particle Accelerator Conference, New York, 1999

[12] J. A. Parrell, M. B. Field, Y. Zhang, and S. Hong, Adv. Cryo. Eng. (Materials) 50B, 2004, 369

[13] P. E. Fabian, N. A. Munshi, and R. J. Denis, "Highly radiation-resistant vacuum impregnation resin systems for fusion magnet insulation", AIP Conf. Proc., vol. 614, 2002, pp. 295-304

[14] F. Wolf, F. Lackner, M. Hofmann, C. Scheuerlein, D. Schoerling, D. Tommasini, "Effect of epoxy volume fraction on the stiffness of $\mathrm{Nb}_{3} \mathrm{Sn}$ Rutherford cable stacks," IEEE Trans. Appl. Supercond., submitted

[15] M. Hofmann, R. Schneider, G.A. Seidl, J. Rebelo-Kornmeier, R.C. Wimpory, U. Garbe, H.-G. Brokmeier, "The new materials science diffractometer STRESS-SPEC at FRM-II, Physica B 385-386, 2006, pp. 1035-1037

[16] M. T. Hutchings, P. J. Withers, T. M. Holden and T. Lorentzen, "Introduction to the Characterization of Residual Stress by Neutron Diffraction", 2005, Boca Raton, FL, CRC Taylor \& Francis

[17] E. Kröner, "Berechnung der elastischen Konstanten des Vielkristalls aus den Konstanten des Einkristalls", Zeitschrift für Physik, vol. 151, no. 4,1958 , pp. $504-18$

[18] C. Scheuerlein, F. Wolf, M. Lorentzon, M. Hofmann, "Direct measurement of $\mathrm{Nb}_{3} \mathrm{Sn}$ filament loading strain and stress in accelerator magnet coil segments", Supercond. Sci. Techn., submitted.

[19] K.R. Keller, J.J. Hanak, "Lattice softening in single crystal $\mathrm{Nb}_{3} \mathrm{Sn}$ ", Phys. Lett., vol. 21, no. 3, 1966, pp. 263-264

[20] H. Wern, R. Johannes, H. Walz, "Dependence of the X-Ray Elastic Constants on the Diffraction Plane", Phys. Stat. Sol. (b), vol. 206, no. 2, 1998, pp. 545-557

[21] W. Voigt, "Ueber die Beziehung zwischen den beiden Elasticitätsconstanten isotroper Körper“, Annalen der Physik, vol. 274, 1889, pp. 573-587

[22] A. Reuss, "Berechnung der Fließgrenze von Mischkristallen auf Grund der Plastizitätsbedingung für Einkristalle“, Z. Angew. Math. Mech., vol. 9, 1929, 49

[23] C. Scheuerlein, F. Lackner, F. Savary, B. Rehmer, M. Finn, P. Uhlemann, "Mechanical Properties of the HL-LHC $11 \mathrm{~T} \mathrm{Nb}_{3} \mathrm{Sn}$ Magnet Constituent Materials", IEEE Trans. Appl. Supercond., vol. 27, no. 4, June 2017, Art. no. 4003007

[24] R. V. Mises, "Mechanik der plastischen Formänderung von Kristallen“, Z. angew. Math. Mech., vol. 8, 1928, pp. 161-185

[25] H. Tanaka1, L. Feng Qun, O. Munekata, T. Taguchi, T. Narita, "Elastic Properties of $\mathrm{Sn}$-Based Pb-Free Solder Alloys Determined by Ultrasonic Pulse Echo Method", Materials Transactions, vol. 46, no. 6, 2005, pp. 1271-1273

[26] C. Scheuerlein, B. Rehmer, M. Finn, C. Meyer, M. Amez-Droz, F. Meuter, K. Konstantopoulou, F. Lackner, F. Savary, J.-Ph. Tock, "Thermomechanical properties of polymers for use in superconducting magnets", IEEE Trans. Appl. Supercond., submitted. 